\title{
EL CABILDO CATEDRALICIO CONQUENSE EN EL SIGLO XIII
}

\author{
JORGE DÍAZ IBÁÑEZ \\ Universidad Complutense de Madrid
}

\begin{abstract}
SUMARIO
Introducción.- I. Fundación y periodo constitucional del cabildo catedralicio hasta las reformas del cardenal Gil de Torres en 1251.- II. Estructura y composición del cabildo catedralicio: 1. Dignidades o personas. 2. El cabildo de canónigos. 3. Racioneros y mediorracioneros. 4. Oficiales y servidores del cabildo.- III. La normativa beneficial.- IV. El cabildo catedralicio y su participación en el servicio litúrgico de la catedral.- V. Rasgos generales del patrimonio rural y urbano del cabildo catedralicio durante los siglos XII y XIII: 1. Las propiedades rurales. 2. Las propiedades urbanas.- Conclusión.
\end{abstract}

\section{INTRODUCCIÓN}

Una de las instituciones que mayor atención merecen, dado su enorme relieve, no sólo eclesiástico, sino también sociopolítico, en el estudio de la Iglesia castellana medieval son los cabildos de las catedrales que encabezaban cada una de las diferentes diócesis de la Corona de Castilla. El cabildo catedralicio era un colectivo de clérigos sólidamente incardinado en la estructura diocesana y con personalidad jurídica bien desarrollada en el Derecho Canónico, cuyos miembros, no siempre presbíteros, eran poseedores de un beneficio económico cuya cuantía estaba en función de la importancia del cargo ostentado.

"Anuario de Estudios Medievales". 27 (1997) 
Fuertemente jerarquizado en su seno, a su cabeza se encontraban las llamadas dignidades o personas, que solían ser los colaboradores más directos del obispo; seguía en importancia el cabildo de canónigos, entre los cuales se valoraba el grado de antiguedad de cara a establecer una diferenciación jerárquica, y finalmente estaban los racioneros y mediorracioneros, aunque a estos últimos se les conocerá más bien como compañeros, sobre todo a partir del siglo XIV. Miembros de una élite eclesiástica, muchos de ellos, aunque no todos, procederán de algunas de las más conspicuas familias de la oligarquía urbana, que veían en esta institución una buena rampa de promoción social.

La misión principal de todos sus integrantes era auxiliar al obispo, contribuir al esplendor litúrgico catedralicio participando en los oficios divinos y rezo de las horas canónicas, así como colaborar en la compleja administración del patrimonio económico perteneciente a la mesa capitular. El colectivo tenía sello propio en reconocimiento de su potestad, independientemente de que, a su vez, muchos de sus miembros poseyesen un sello personal a título individual' ${ }^{1}$. Teóricamente debían elegir al obispo, así como asegurar la marcha de la diócesis en época de sede vacante, aunque en la práctica dicha potestad electiva estuvo fuertemente limitada.

\footnotetext{
'En lo relativo a este punto, y a modo de ejemplo, resulta enormemente ilustrativa una serie de sellos del siglo XIII, de gran riqueza iconográfica, que aún se conservan en el documento de elección del obispo de Cuenca Pedro Lorenzo (7-XII-1261), custodiado en el Archivo Capitular de Toledo. El documento conserva un total de 7 sellos, uno del cabildo catedralicio conquense y el resto de canónigos y dignidades de Cuenca. Existía un octavo sello, que se ha perdido. Estos sellos, ordenados de izquierda a derecha, son los siguientes: 1) Sello del maestro Juan, canónigo de Cuenca. Aparece un águila con las patas abiertas y alas extendidas. Encima una estrella y abajo un cáliz. El águila tiene influjo iconográfico del escudo imperial de los Staufen. 2) Sello de Aparicio, canónigo de Cuenca. Cera natural. Aparece una rosa de ocho pétalos entre los cuales encajan las letras AVE STELLA, excepto la T, en la punta e invertida. En la parte superior del campo aparece una cruz potenzada. 3) Sello del maestrescuela de Cuenca, Adán López. Cera natural. Personaje de $3 / 4$ a la derecha, sedente en un banco. Dándole la espalda aparece un clérigo de pie sobre una peana, con manípulo y un libro entre las manos. Por encima hay una luna. 4) Sello del arcediano de Huete. Gonzalo García. Cera roja. Aparece el arcángel San Miguel con nimbo de puntos, alanceando al dragón con lanza rematada en cruz patente. 5) Sello del cabildo catedralicio conquense, en el centro. Es más grande que el resto de los sellos. Cera natural. Sedente en una especie de trono rematado por cabezas de perros aparece la Virgen con velo y diadema de tres florones, con cetro flordelisado apoyado sobre el hombro, y con el niño de frente sentado sobre la pierna izquierda, nimbado y bendiciendo. 6) Sello de Pascual, chantre de Cuenca. Cera natural. Cepa de vid con flores y sarmientos. Sobre el tronco una estrella de seis rayos y encima un cáliz a cuyos lados hay dos aves afrontadas. 7) Sello de Martín González, arcediano de Alarcón. Aparece un serafín con nimbo radiante membrado de seis alas, entre dos cipreses frutados que reposan sobre un listel. En la parte inferior del campo, un orante de perfil. Archivo Catedralicio de Toledo (ACT), X.1.E.2.4
} 
A continuación sólo se expondrán, y de forma muy sucinta, algunos rasgos básicos de la organización administrativa y económica del cabildo catedralicio conquense desde su fundación a fines del siglo XII y a lo largo de la siguiente centuria, pero no será posible, por razones de espacio, detenernos en el estudio detallado de otra cuestión de suma importancia como fue la proyección sociopolítica del cabildo catedralicio mediante su temprana integración en todo un complejo sistema de relaciones de poder de la más variada índole. Así, pues, el análisis de las páginas siguientes se centrará exclusivamente en el estudio de los rasgos organizativos arriba señalados.

\section{FUNDACIÓN Y PERIODO CONSTITUCIONAL DEL CABILDO CATEDRALICIO HASTA LAS REFORMAS DEL CARDENAL GIL DE TORRES EN 1251}

Conquistada en 1177 la ciudad de Cuenca por el rey de Castilla Alfonso VIII, poco tiempo después, el 1 de junio de 1182, el papa Lucio III, mediante sendas bulas enviadas al monarca castellano y al obispo electo de Cuenca don Juan Yáñez, concedería la anexión de las antiguas sedes visigodas de Ercávica y Valeria a la de nueva creación de Cuenca ${ }^{2}$. Al año siguiente, a través de una nueva bula fechada el 15 de mayo de 1183, Lucio III autorizó a don Juan Yáñez para fundar el primer cabildo de canónigos y organizar las iglesias de Cuenca ${ }^{3}$. De esta forma, muy poco después, el 28 de julio del mismo año, y como primer hecho señalado en el proceso de organización de la nueva diócesis, el obispo don Juan instituirá el primer cabildo catedralicio, asignándole sus primeras rentas ${ }^{4}$.

Del análisis del documento de creación del cabildo se desprende, en primer lugar, que el colectivo estaba formado inicialmente por un total de 16 canónigos, que eran regulares. Lo primero que llama la atención es la procedencia geográfica de los nuevos canónigos, casi todos ellos de la

\footnotetext{
${ }^{2}$ Archivo Catedralicio de Cuenca (ACC), caj. 1, n 1 y 2. A. ChaCón GÓmEZ-MONEDERO, Las bulas de fundación del obispado de Cuenca, en "Cuenca" (revista publicada por la Diputación Provincial de Cuenca), 25/26 (1985), docs. 1 y 2.

${ }^{3} \mathrm{ACC}$, caj. 1, n"3. A. ChaCÓN, Las bulas de fundación, doc. n" 3 .

${ }^{4}$ ACC, caj. 1, n" 4. A. ChaCÓN, op. cit., doc. n" 4 .
} 
Meseta Norte, lo cual debe encuadrarse dentro de las características propias de la repoblación conquense en lo que se refiere a la procedencia de los pobladores. Asimismo, debe ser puesta de manifiesto la mención que el documento hace de un tal Rodrigo de Castro y cierto Juan de Lara, representantes ambos de la vieja nobleza castellana, con lo cual no cabe sino sospechar que detrás de su nombramiento como canónigos estuvo el propio monarca castellano. Por otro lado, también hay que ver la mano del monarca en el nombramiento del maestro Giraldo, canciller real.

Muy poco después, y seguramente durante el mismo pontificado de don Juan Yáñez, o en el de su sucesor, San Julián, se crearían las primeras dignidades del cabildo, que inicialmente fueron ocho: prior, que en 1215 ya había sido sustituído por el deán; arcediano de Cuenca; arcediano de Huete, que ya existía antes de la conquista de Cuenca como una dignidad dependiente del cabildo catedralicio toledano; arcediano de Alarcón; arcediano de Cañete que, como pronto veremos, en 1215 ya había sido sustituído por el de Moya; chantre; maestrescuela y tesorero. Tras su creación, este número de dignidades se mantendrá inalterable hasta el siglo XV, en que se instituirán las nuevas dignidades de abad de Santiago y abad de la Sey.

Por lo que respecta a las raciones enteras y medias, es probable que su creación tuviese lugar también en el pontificado de don Juan Yáñez, aunque sobre ello no nos ha quedado constancia documental. Desde luego su presencia ya aparece documentada en los estatutos de San Julián de 1201, y pronto su número aumentaría hasta tal punto que en 1251 sería necesaria una intervención del cardenal Gil de Torres para frenar este excesivo aumento.

En cuanto a las bases económicas iniciales del nuevo cabildo, a través del citado documento del 28 de julio de 1183 don Juan asignó las primeras rentas para el refectorio capitular, siendo las siguientes: la mitad de los diezmos de todas las iglesias de Cuenca y sus aldeas; la mitad de los molinos y veinte vacas; la mitad de todos los réditos reales donados por el rey, es decir, de los diezmos de pan, vino, quintos, portazgo y caloñas; un majuelo junto al Júcar y la mitad de una heredad en la hoz del Huécar; y finalmente la tercera parte de los diezmos de la capilla y todas las oblaciones de pan y vino que se ofrezcan en el altar de la misma. Sin duda el montante económico fundamental de esta primera donación estaría constituído por la mitad de los diezmos de todas las iglesias de Cuenca y sus aldeas. A su vez, del documento se desprende que, evidentemente, ya desde el primer momento se establecería una mesa capitular con rentas propias independiente 
de la mesa episcopal, y ello debe ser puesto en relación con la división de mesas que precisamente durante la segunda mitad del siglo XII se estaba imponiendo en casi todas las catedrales de Castilla y León.

Mucha mayor importancia tendrá una segunda donación de bienes y rentas a favor del cabildo realizada por don Juan Yáñez el 16 de enero de $1195^{5}$, a través de la cual también se confirman algunas de las donaciones realizadas por el obispo en 1183. Las rentas que en esta ocasión se asignan van dirigidas a la obra del refectorio de los canónigos y al vestuario. Para el refectorio el documento enumera las siguientes rentas:

-La mitad de todos los diezmos de las iglesias de Cuenca y sus aldeas, fundadas y por fundar. En las iglesias del término de Cuenca donde los canónigos recibieran diezmos los podrán retener en su totalidad a perpetuidad.

-La mitad de todos los réditos reales donados por el rey.

-Una molino al otro lado del Júcar y la mitad de una heredad situada en la hoz del Huécar.

-La tercera parte de los diezmos de la capilla y todas las oblaciones de pan y vino que se ofrezcan en el altar de la misma.

-La tercera parte de los diezmos de Uclés y su término.

-Varias aceñas en el Júcar, cerca de Cuenca.

-Villarseco y su término.

-El obispo no tomará nada de las donaciones hechas por particulares a favor del cabildo a cambio de aniversarios. siguientes:

En cuanto a las rentas que se asignan para el vestuario, son las

-La mitad de los diezmos de todas las iglesias de Cañete y su término, y todos los diezmos del portazgo, quintos y salinas de Cañete. Monteagudo.

-Los diezmos del portazgo de Paracuellos y de las salinas de

-La mitad de los diezmos de las iglesias de Alarcón y todos los diezmos de las iglesias fundadas y por fundar en término de Alarcón.

En este segundo reparto de rentas a favor del cabildo puede observarse fácilmente cómo también será el diezmo el montante económico fundamental, sentándose de este modo las bases del sistema de reparto decimal en la diócesis conquense. Así, el cabildo tendrá derecho a percibir

${ }^{5} \mathrm{ACC}$, caj. 2, no 23. 
diezmos en los arcedianatos de Cuenca, Cañete-Moya, y Alarcón, además de Uclés, quedando reservada en exclusiva al obispo la percepción de diezmos en el arcedianato de Huete. Por supuesto, paralelamente a estas primeras donaciones episcopales, el cabildo catedralicio también se vería beneficiado por otras donaciones y privilegios reales.

Dentro de esta etapa inicial, destaca también, como uno de los actos administrativos más señalados, el otorgamiento y confirmación que en 1201 hizo el obispo San Julián al cabildo catedralicio de los primeros estatutos capitulares conocidos, en los cuales, entre otras cosas, se establece la normativa de residencia y condiciones para ausentarse que habrían de cumplir en adelante los canónigos, figurando también diversas normas sobre arrendamiento por los propios canónigos de las heredades de los aniversarios, así como sobre la forma de distribución de las rentas obtenidas por esta vía $^{6}$.

Además de todo ello, durante este periodo se consolidaría la jerarquización interna del cabildo, se iría delimitando su capacidad legislativa, la forma en que habrían de desarrollarse las reuniones capitulares y el derecho teórico del cabildo a elegir obispo y administrar los bienes de la mesa episcopal en época de sede vacante.

Más arriba se ha señalado cómo inicialmente los canónigos de Cuenca fueron regulares. De hecho los primeros documentos siempre aluden al convento de canónigos. Así, en un documento del 5 de noviembre de 1210 del obispo don García sobre el testamento de los canónigos, se habla de "conventui canonicorum"7, y dicha denominación aún se sigue utilizando en $1224^{8}$.

No obstante, en la documentación nunca aparecen alusiones referentes a la realización de vida en común por parte de los canónigos, ni a la existencia de una casa donde vivieran conjuntamente, por lo que cabe sospechar que en la práctica el tipo de vida que llevaban los primeros canónigos debía de ser bastante similar a la de los canónigos seculares. De

\footnotetext{
${ }^{6} \mathrm{ACC}$, caj. 2, $\mathrm{n}^{\circ}$ 30. Este documento, al llevar la suscripción autógrafa de San Julián, ha sido tradicionalmente venerado como reliquia por parte de la Iglesia conquense.

${ }^{7} \mathrm{ACC}$, caj. $4, \mathrm{n}^{\circ} 62$

${ }^{8} \mathrm{ACC}$, caj. $4, \mathrm{n}^{0} 55$. Es un documento por el que el deán y cabildo arriendan a doña W unas casas que les había dejado el canónigo don Asensio para su aniversario, al precio de 10 mencales anuales. En el documento aparece la siguiente expresión: "nos G. decanus totusque conchensis ecclesie conventus".
} 
hecho en la primera mitad del siglo XIII se observa una fuerte tendencia a la secularización en otros cabildos catedralicios castellanos. Desde luego a mediados de la citada centuria las alusiones documentales al convento de canónigos desaparecen por completo, por lo que cabe pensar que hacia estas fechas, como muy tarde, los canónigos conquenses ya estaban plenamente secularizados.

El final de toda esta etapa, a la que podríamos denominar como periodo constitucional, vendría dado por la intervención del cardenal Gil de Torres sobre la Iglesia conquense que tuvo lugar en 1251, y que debe ser enmarcada dentro del proceso de transformación, delimitación de funciones $\mathrm{y}$ número de beneficios que experimentaron casi todos los cabildos catedralicios castellanos a mediados del siglo XIII, proceso que no venía a ser sino un intento de aplicación de las disposiciones del IV Concilio Lateranense.

Desde principios del siglo XIII el cabildo catedralicio conquense, al igual que lo sucedido en otros lugares, comenzó a experimentar un progresivo aumento en el número de racioneros y mediorracioneros, que en 1251 era ya excesivo con respecto a lo que las rentas capitulares podían dar de sí. Fue por ello por lo que este mismo año tuvo lugar una intervención del cardenal Gil de Torres sobre la Iglesia conquense, a raíz de la cual se determinó que el número de racioneros fuera de diez y el de mediorracioneros de doce, prohibiéndose además que en el futuro se trate de introducir cualquier cambio sobre este número de beneficios ${ }^{9}$. En este sentido conviene llamar la atención sobre el alto grado de estabilidad posterior en el número de beneficios, dado que el cronista conquense del siglo XVII Juan Pablo Mártir Rizo nos indica que en su época el número de raciones seguía siendo de diez y el de mediasrraciones de doce ${ }^{10}$.

En cuanto al número de canónigos, 16 inicialmente, sabemos con completa seguridad que en el siglo XV era ya de 26 . No obstante, y aunque no se conserva el documento de creación de las diez nuevas canonjías sobre las 16 iniciales, no sería demasiado aventurado sospechar que dicho aumento pudo haber tenido lugar hacia mediados del siglo XIII, dado que hemos visto cómo por esa misma época el número de raciones se había visto afectado por

${ }^{9}$ J.M. NIETO SORIA, El intervencionismo pontificio sobre la Iglesia conquense en el siglo XIII, "Hispania", XLV/159 (1985), pp. 54-55.

${ }^{10} \mathrm{~J} . \mathrm{P}$. MÁrTiR RIzO, Historia de la muy noble y leal ciudad de Cuenca, Madrid, 1629, pp. 122-123. 
una clara tendencia al alza. De esta forma, dando por válida esta hipótesis, como muy tarde en el siglo XIV el número de canonjías quedaría establecido en 26 .

En definitiva, en este periodo constitucional, que llegaría hasta mediados del siglo XIII, se crearían las bases fundamentales para el posterior desarrollo y maduración de la institución capitular que, aunque experimentará algunas reformas futuras, en general mantendrá siempre los esquemas básicos de organización perfilados durante esta etapa.

\section{Dignidades o personas}

En la cúspide del cabildo catedralicio se encontraban las llamadas dignidades o personas, que ostentaban dentro del colectivo una posición de supremacía. Ya se ha señalado que inicialmente las dignidades del cabildo conquense fueron ocho, a las que en el siglo $\mathrm{XV}$ se añadirían las nuevas dignidades de abad de Santiago y abad de la Sey, creándose ya en la primera mitad del siglo XVI otras tres nuevas dignidades: arcipreste, prior y capellán mayor. Así, a mediados de esta última centuria el número de dignidades del cabildo sería ya de trece.

Cuando no eran absentistas, frecuentemente el obispo escogía de entre estas personas a sus colaboradores más directos para el gobierno de la diócesis. Hay que señalar también que por lo general estas dignidades, además de su prebenda por tal cargo, poseían también una canonjía en el cabildo catedralicio conquense, siendo además frecuente el caso de que también poseyesen otros beneficios dentro o fuera de la diócesis conquense.

Según el Derecho Canónico, en principio, la provisión de las dignidades estaba reservada al obispo, y en ciertos casos al papa. Esto era la teoría. No obstante, durante el siglo XIII en Cuenca serán frecuentes las intromisiones del arzobispo toledano y del monarca castellano, y durante las dos centurias siguientes a las intervenciones del rey se unirán cada vez con más fuerza las frecuentes reservas pontificias. Veamos a continuación cuáles eran los rasgos más característicos de estas dignidades.

\section{A) Deán}

En los momentos iniciales este cargo, el de máximo relieve dentro de la jerarquía capitular, recibía el nombre de prior, y así se menciona en 
los estatutuos otorgados por San Julián al cabildo en $1201^{11}$. En cambio en 1215 ya aparece por primera vez el deán confirmando un documento ${ }^{12}$.

Cuando el cabildo se reunía en el coro de la catedral, esta dignidad presidía el lado llamado Coro del deán, frente al otro lado que era el Coro del obispo. Si asistía, presidía siempre las reuniones capitulares, y en general debía supervisar la buena marcha del colectivo capitular.

En cuanto a la valoración económica del deanato de Cuenca, quizá pueda servir de orientación el pago realizado el 15 de diciembre de 1324 por el deán conquense Fernando García, quien en dicha fecha satisfizo a la Cámara Apostólica 150 florines de oro por los frutos de un año de su dignidad $^{13}$.

\section{B) Arcediano de Cuenca}

Ocupaba el primer lugar en el Coro del obispo y, al menos en teoría, debía ser diácono ${ }^{14}$. Parece probable la institución de esta dignidad desde muy poco después de la creación del cabildo catedralicio, probablemente durante el mismo pontificado de don Juan Yáñez o, como muy tarde, durante el de San Julián. Desde luego a comienzos del siglo XIII esta dignidad ya existía, y sabemos que el primero en ostentarla fue un personaje llamado don Lope $^{15}$. Al igual que el resto de los arcedianos, parece que tenía cierta potestad jurisdiccional, pero las escasas referencias que aparecen en la documentación no permiten establecer con exactitud dónde estaban los límites de dicha potestad.

\footnotetext{
"ACC, caj. 2, n' 30.

${ }^{12} \mathrm{ACC}$, caj. $3, \mathrm{n}^{\circ} 41$. Se trata de una concordia entre el obispo don García y los clérigos de Huete, que está fechada en Cuenca el 23 de julio de 1215

${ }^{13} \mathrm{~J}$. GoÑı GazTAmBIDE, El fiscalismo pontificio en España en tiempo de Juan XXII, "Anthologica Annua", 141 (1966), p. 82.

${ }^{14}$ D. Ramírez DE VILlaescusa, Constituciones synodales del obispado de Cuenca, Cuenca, 1531 , f. 5 r.

${ }^{15} \mathrm{ACC}$, caj. $2, \mathrm{n}^{\mathrm{0}} 28$. Se trata de un documento de principios del siglo XIII por el que D. Pérez, canónigo de Cuenca, cede al cabildo catedralicio, para reparar sus baños del Júcar, 100 mencales de los 1000 que le había dejado su tío don Lope, primer arcediano de Cuenca, para comprar unas tierras con las que dotar ciertas festividades religiosas.
} 


\section{C) Arcediano de Huete}

Esta dignidad ya existía antes de la conquista de Cuenca, pues al ser conquistado Huete en tiempos de Alfonso VII "El Emperador", la villa y su extenso alfoz se habían organizado como un arcedianato dependiente en un principio de Toledo. Así, en junio de 1167 nos encontramos a Juan, arcediano de Huete, haciendo donación de la aldea de Córcoles con todos sus términos al monasterio cisterciense de Santa María de Monsalud ${ }^{16}$.

Se trata de uno de los pocos documentos anteriores a la conquista de Cuenca en que se hace mención del arcediano de Huete. Más tarde, al ser fundada la diócesis conquense, el arcedianato de Huete pasaría a integrarse en ella con todo su amplio alfoz, desvinculándose de este modo de una dependencia directa hacia la metrópoli toledana y pasando a formar parte el arcediano de Huete de las dignidades del cabildo conquense.

Esta dignidad ocupaba el segundo lugar en el Coro del deán, situándose a continuación de este último, y debía ser al menos diácono ${ }^{17}$. Tras la conquista de Cuenca, uno de los testimonios más tempranos que poseemos sobre este cargo es el de un tal Lope Rodrigo, sobrino del obispo García Ruiz, que en 1215 figura como arcediano de Huete ${ }^{18}$. Pero entre los personajes que ostentaron el título de arcediano de Huete hay que destacar ante todo a Gil Álvarez de Albornoz, futuro arzobispo de Toledo y cardenal, el cual desde 1325, siendo aún muy joven, ya aparece ostentando dicha dignidad, que poseería hasta el momento de su muerte en 1367, y ello a pesar de que, debido a sus múltiples empresas al servicio de la Monarquía castellana y del Papado, pronto dejaría de cumplir los deberes a que estaba teóricamente obligado con respecto a su cargo arcedianal.

\section{D) Arcediano de Alarcón}

La existencia de esta dignidad aparece documentada al menos desde $1215^{19}$, aunque es probable que su creación tuviese lugar durante el pontificado de don Juan Yáñez o el de su sucesor, San Julián. Esta dignidad

\footnotetext{
${ }^{16}$ Archivo Histórico Nacional (AHN), Clero, carp. 569, n⿳0 20; libro 4235, ff. 13v-14v.

${ }^{17}$ D. Ramírez de Villaescusa, Constituciones synodales, $\mathrm{f}$. $5 \mathrm{r}$.

${ }^{18} \mathrm{~J} . \mathrm{M}$. NIETO SORIA, El intervencionismo pontificio, p. 47.

${ }^{19} \mathrm{ACC}$, caj. 3, n 41 .
} 
ocupaba el tercer lugar en el Coro del obispo, situándose después del chantre, y debía poseer al menos la orden del diaconado ${ }^{20}$.

\section{E) Arcediano de Cañete-Moya}

La creación del efímero arcedianato de Cañete probablemente tuvo lugar después de 1190, año en que esta localidad pasó a integrarse en la jurisdicción eclesiástica conquense, pues hasta entonces había dependido del obispo de Albarracín. A partir de este momento algunos documentos revelan la existencia del arcediano de Cañete, aunque esta dignidad duraría muy poco tiempo, dado que pronto fue sustituída por el arcediano de Moya. Según Muñoz y Soliva el arcediano de Cañete fue sustituído por el de Moya en $1269^{21}$. No obstante, esta fecha está equivocada, pues, impulsada y autorizada por Alfonso VIII la repoblación de Moya desde 1210, muy poco después, ya en 1215, nos encontramos al arcediano de Moya confirmando un documento ${ }^{22}$. En enero de 1224 el cargo, con evidentes funciones repobladoras, lo ocupaba un tal D. Pérez ${ }^{23}$.

Esta dignidad ocupaba el tercer puesto en el Coro del deán, situándose a continuación del arcediano de Huete, y debía poseer el grado de diácono ${ }^{24}$.

\section{F) Chantre}

La creación de esta dignidad debe remontarse a la etapa inicial del cabildo catedralicio, y probablemente tuvo lugar durante el pontificado de don Juan Yáñez o el de San Julián. Ocupaba el segundo lugar en el Coro del obispo, a continuación del arcediano de Cuenca, teóricamente debía ser presbítero, y su misión era dirigir gran parte de las actividades del coro y

\footnotetext{
${ }^{20}$ D. Ramírez de Villaescusa, Constituciones synodales, f. $5 \mathrm{r}$.

${ }^{21} \mathrm{~T}$. MUÑoz Y SOliva, Noticias de todos los ilustrísimos señores obispos que han regido la diócesis de Cuenca, Cuenca, 1860, p. 14.

${ }^{22} \mathrm{AHN}$, Servicio Nacional de Microfilmes, rollo 14227. Se trata de una concordia, fechada el 25 de abril de 1215, entre el obispo de Cuenca don García y los clérigos de las aldeas del término de Huete. Entre los confirmantes figura la suscripción autógrafa del arcediano de Moya, "Modiensis archidiaconus"

${ }^{23} \mathrm{AHN}$, OOMM-Uclés, carp. 98, $\mathrm{n}^{0} 8$.

${ }^{24}$ D. RAmírez DE VILlaescusa, Constituciones synodales, f. $5 r$.
} 
organizar la ejecución del canto litúrgico, función en la que frecuentemente le sustituía un sochantre, que era un delegado que actuaba en nombre del chantre cuando éste estaba ausente ${ }^{25}$.

\section{G) Tesorero}

Esta dignidad es probable que se crease en la fase inicial de existencia del cabildo catedralicio, y a medida que avanza el siglo XIII va estando más documentada. Ocupaba el cuarto lugar en el Coro del obispo, situándose a continuación del arcediano de Alarcón, y en principio debía ser presbítero. Se trata sin duda de la dignidad del cabildo catedralicio conquense cuyas competencias, junto con las del canónigo obrero, aparecen delimitadas con mayor precisión y amplitud a lo largo de la normativa capitular.

La primera legislación al respecto data del 25 de diciembre de 1282 , fecha en que el obispo don Gonzalo García y el cabildo catedralicio precisaron las competencias que en adelante habrían de tener el obrero y tesorero de la catedral, dado que hasta entonces dichas competencias no acababan de estar del todo claras, lo cual daba lugar a diversos problemas. Así, entre las obligaciones que se establece que en adelante habrá de cumplir el tesorero tenemos las siguientes: dar sogas para las campanas de la catedral y adobe para los badajos; cuidar bien los libros de la iglesia; ocuparse de los inciensarios, ciriales, ampollas y otros objetos litúrgicos; hacer coser y lavar las vestimentas y paños de la iglesia; dar incienso, candelas, óleo y cuerdas para las tres lámparas que están entre el altar y el coro; dar paja en invierno para el coro; hacer barrer, regar y desollinar la iglesia, y hacer limpiar las tumbas de los obispos; encargarse de tener en la sacristía "buenos omes e honestos" 26 .

\footnotetext{
${ }^{25}$ Uno de los testimonios más antiguos que se conservan sobre la existencia de un sochantre en Cuenca data del 18 de julio de 1302, fecha en la cual el cabildo catedralicio vendió en almoneda a Alvar Sánchez, canónigo y sochantre de la catedral, unas casas en la "calleja del Canto", al precio de 600 mrs. ACC, siglo XIV, n 64.

${ }^{26} \mathrm{ACC}$, caj. 11, no 197 , ff. $54 \mathrm{r}-55 \mathrm{r}$
} 


\section{H) Maestrescuela}

La existencia del maestrescuela está documentada al menos desde $1215^{27}$, pero es probable que su creación date del pontificado de don Juan Yáñez o del de San Julián. Ocupaba el cuarto lugar en el Coro del deán, situándose a continuación del arcediano de Moya, y en teoría debía ser presbítero.

\section{El cabildo de canónigos}

El cabildo de canónigos, del que casi siempre formaban parte las dignidades en función de la posesión de una canonjía, era la corporación catedralicia por excelencia, con personalidad jurídica propia que le era reconocida por el Derecho Canónico y las leyes de la Corona de Castilla. Su función esencial era contribuir a la magnificencia del culto catedralicio mediante la asistencia a coro, misa, y otras celebraciones religiosas, así como colaborar en diversos aspectos de la organización de la catedral y administración del patrimonio de la mesa capitular. Teóricamente elegían al obispo, aunque esta facultad siempre estuvo muy limitada debido a las frecuentes intromisiones regias y pontificias.

Sus funciones administrativas se plasmaban en diversos estatutos y mandatos que en muchos aspectos estaban bajo la dependencia de la jurisdicción episcopal, y a través de los cuales se ordenaba el servicio litúrgico de la catedral y se regulaba la organización interna del propio colectivo, así como la gestión económica de los bienes que permitían asegurar el culto y el sustento de los servidores del mismo.

En cuanto al número de integrantes, ya hemos visto cómo inicialmente el cabildo contaba con 16 canónigos, tal como se desprende del documento fundacional de don Juan Yáñez de 1183, y sabemos con completa seguridad que en el siglo $\mathrm{XV}$ eran ya $26^{28}$. No obstante, y aunque no se

\footnotetext{
${ }^{27} \mathrm{ACC}$, caj. 3, no 41.

${ }^{28}$ Mateo López alude a la creación de las 10 nuevas canonjías sobre las 16 iniciales en un momento indeterminado, lamentándose de no haber podido encontrar el documento de creación de las 10 nuevas canonjías. M. LóPEz, Memorias históricas de Cuenca y su obispado, I, Madrid, 1949 (el manuscrito original es de fines del siglo XVIII), p. 189. En las Actas Capitulares del 19 de agosto de 1493 aparece una frase que alude a "todos veynte e seys canonigos" de Cuenca. ACC, Actas Capitulares de 1493, f. 193v. Pero ya antes, por ejemplo en el Libro de Pitancería del año 1439, consta la asistencia a coro en ciertos días de al menos
} 
conserva el documento de creación de las diez nuevas canonjías sobre las 16 iniciales, no sería demasiado aventurado sospechar que dicho aumento pudo haber tenido lugar hacia mediados del siglo XIII, dado que hemos visto cómo por esa misma época el número de raciones se había visto afectado por una clara tendencia al alza.

Ahora bien, al menos desde el siglo XIV fue muy frecuente que las dignidades poseyesen alguna de estas canonjías, por lo que hay que tener en cuenta que, si había 26 canónigos, varios de ellos eran también dignidades. Aunque carecemos de datos que nos permitan afirmar que todas las dignidades siempre poseyeron también una canonjía, lo cierto es que muchas veces la documentación al referirse a las dignidades también alude a ellas como "canónigos". Así, pues, puede decirse que al menos varias de las dignidades de Cuenca, incluso quizá todas, acabarían poseyendo una canonjía, pero no tenemos datos que nos permitan precisar con exactitud la cronología de este proceso o las excepciones a la norma general que quizá pudieron darse.

Hay que llamar la atención sobre la enorme estabilidad posterior que tendrá este número de canónigos que, una vez fijado en 26 , se mantendrá invariable durante siglos. Buena prueba de ello es el testimonio que recoge en sus Memorias Mateo López, autor que señala que en su época - fines del siglo XVIII- aún se mantenía el número de 26 canonjías en la catedral conquense $^{29}$.

\section{Racioneros y mediorracioneros}

Los racioneros y mediorracioneros -estos últimos conocidos más bien como compañeros - constituían el escalafón inferior del cabildo catedralicio. Tal como se señaló antes, a través de la intervención del cardenal Gil de Torres de 1251, el número de raciones quedaría establecido en diez, y el de mediasrraciones en doce, lo cual se mantendría invariable durante siglos.

Su misión era ayudar al cabildo de canónigos en el culto y administración catedralicios, y su presencia era importante debido a la frecuente

20 canónigos, y si a ello añadimos las canonjías que sin duda poseían varias dignidades que también se citan, obtendríamos como resultado que en ese año el número de canónigos, documentadamente, ya sería también de 26. ACC, Libro de Pitancería de 1439, ff. 134v-135r.

${ }^{29}$ M. LÓPEZ, Memorias, I, p. 190. 
ausencia de canónigos y dignidades. Muy a menudo ejercían cargos como procuradores del cabildo, mayordomos, visitadores, etc, desempeñando funciones de gran utilidad en la compleja administración del patrimonio del cabildo.

En cuanto a la colación de las raciones y mediasrraciones, que frecuentemente recaían en criados y familiares del obispo o dignidades, en general corría a cargo tanto del obispo como del cabildo catedralicio, al igual que sucedía con las canonjías, exceptuando, por supuesto, las reservas pontificias que a partir del siglo XIV serán cada vez más frecuentes. Esta colación podía llevarse a cabo bien conjuntamente por el obispo y cabildo, o bien podían alternar colaciones realizadas por el obispo con otras realizadas por el cabildo.

\section{Oficiales y servidores del cabildo}

Finalmente, como último punto en el análisis de la jerarquía capitular, no queda sino aludir a la temprana existencia de toda una serie de cargos al servicio del cabildo. Efectivamente, la complejidad organizativa de la institución capitular y del culto catedralicio hizo pronto necesaria la presencia de diversos servidores para el culto así como de algunos oficiales para la administración y distribución del patrimonio y rentas capitulares. Algunos de estos cargos de oficiales podían ser desempeñados por los propios capitulares, como por ejemplo sucedió con los cargos de mayordomo, canónigo obrero, visitador y procurador del cabildo, ya existentes durante el siglo XIII. En cuanto a los servidores del culto catedralicio cabe destacar la temprana presencia de capellanes, canónigos extravagantes ${ }^{30}$, mozos de coro, sacristán, portero y campanero, entre otros.

\footnotetext{
${ }^{30}$ El canónigo extravagante era un cargo honorífico remunerado con una pequeña cantidad de dinero. Participaban en el culto catedralicio pero no tenían voz ni voto en las reuniones capitulares, por lo que en nada se pueden asimilar al cabildo de canónigos. Su misión fundamental era asistir al coro y engrandecer con su presencia el rezo de las horas, dadas las frecuentes ausencias por parte de los canónigos titulares. Para el caso conquense su existencia aparece documentada por lo menos desde el año 1264. ACC, caj. 7, n 123.
} 


\section{LA NORMATIVA BENEFICIAL}

El beneficio capitular consistía en un grupo de bienes y rentas de mayor o menor cuantía económica que recibía cada miembro del cabildo catedralicio en función de su puesto jerárquico en la corporación y oficio eclesiástico desempeñado. El beneficio, además, solía estar compuesto por ingresos procedentes de muy diversas fuentes de renta, y no era inusual la acumulación de varios beneficios por una misma persona. En general los componentes básicos del beneficio capitular fueron uno o varios préstamos situados sobre las rentas decimales de algunas parroquias de la ciudad o diócesis, el vestuario estimado en una cuantía determinada de maravedís al año, y una o varias raciones situadas sobre las rentas de la mesa capitular.

Ahora bien, una vez concedido el beneficio capitular a una determinada persona, su percepción quedaba, al menos en teoría, sujeta a toda una serie de normas que pronto comenzaron a ser precisadas con exactitud. La primera normativa que para la Iglesia de Cuenca se conserva sobre el particular data de fecha muy temprana, y se encuentra recogida en los ya mencionados estatutuos que otorgó San Julián al cabildo catedralicio en 1201, que son probablemente los primeros que poseyó el colectivo capitular. Entre los aspectos en ellos tratados figuran bastantes puntos tocantes a normativa beneficial, que son los siguientes:

-En adelante serán tenidos por residentes todos aquellos canónigos que tengan en Cuenca su residencia principal.

-El canónigo que no sea residente y viniese a residir en la Iglesia, habrá de permanecer al menos durante medio año en Cuenca para ser tenido por residente, y en este medio año no tendrá derecho a percibir la renta del vestuario. Pasado dicho plazo, y si sirve bien, ya podrá ganar el vestuario.

-Si algún residente, por asunto de utilidad propia o ajena, se ausentase con licencia del prior, durante un mes no se le tendrá en cuenta la ausencia. Pero si tarda más de un mes en volver, en función de la mayor o menor dilación podrá perder el vestuario, excepto si la causa de mayor tardanza fuese enfermedad u otro motivo grave que constituya excusa legítima.

-El canónigo que no asista a los funerales de difuntos, si está en la ciudad perderá la mitad de lo que le habría correspondido ganar si hubiese asistido, y si tampoco acude a la procesión o entierro perderá la otra mitad, excepto si previamente tuviese licencia del prior y cabildo para ausentarse 
por causa legítima. Pero el canónigo que no esté en la ciudad tendrá durante un mes derecho a los estipendios de los funerales.

-Todos los canónigos que acudan a estudiar a algún lugar serán tenidos por residentes, y cobrarán como si estuviesen presentes. Igual norma regirá con los que se ausenten para realizar peregrinaciones sagradas.

-Los canónigos residentes que por asunto propio o concerniente a la Iglesia de Cuenca acudiesen a visitar al papa, serán tenidos por residentes y cobrarán su beneficio durante todo el tiempo que dure el viaje.

-El canónigo o racionero que apele al rey sobre asunto propio o de la Iglesia de Cuenca podrá recibir enteramente las distribuciones y rentas durante un mes como si residiese, e igual sucederá con el que apele al arzobispo toledano.

-Respecto al que apele ante el obispo, gozará durante quince días de las distribuciones y rentas en caso de haber empleado dicho tiempo para la resolución de su negocio.

-El canónigo o racionero que sea desterrado de la ciudad y no se atreva a entrar en ella, podrá gozar de su ración como si residiese en la Iglesia, independientemente del lugar donde viva fuera de los muros de la ciudad.

-Si algún residente, canónigo o racionero, estuviese impedido por enfermedad o cautiverio, tendrá derecho a percibir la ración de su prebenda como si asistiese.

-Los que estén auxiliando al obispo serán tenidos por residentes, y podrán gozar de los funerales y vestuarios.

-El canónigo a racionero residente que muera gozará de una ración entera desde el día de su muerte hasta un año después. Previamente dicho canónigo o racionero, al hacer testamento, habrá de designar a un canónigo para que se encargue de que, con los emolumentos de dicha ración, se sufrague su entierro y misas que se hayan de decir. Si muriese sin testamento, la ración quedará a disposición del cabildo y se empleará en decir misas a favor del difunto ${ }^{31}$.

De esta forma, a través de estos estatutos de 1201, quedaba ya firmemente establecida la normativa básica que durante cierto tiempo habría de regir en la Iglesia de Cuenca en lo relativo a las obligaciones de

\footnotetext{
${ }^{31}$ Una traducción al castellano de estos estatutos de San Julián está recogida en: B. AlCázAR, Vida, virtudes y milagros de San Julián, segundo obispo de Cuenca, Madrid, 1692 pp. 269-273.
} 
residencia de los canónigos y racioneros para poder tener derecho a su beneficio, normativa que, en muchos aspectos, se basaba en la legislación general establecida por el Derecho Canónico sobre esta materia. Por supuesto, estas normas de 1201 sufrirían variantes y modificaciones posteriores, pero fueron una base para la legislación de los siglos siguientes.

En relación con la obligatoriedad de residencia para recibir la renta del vestuario, la siguiente legislación al respecto que cabe destacar es la que se produjo a raíz de una intervención del cardenal Juan de Abbeville sobre la Iglesia conquense que tuvo lugar el 22 de junio de 1229. Este cardenal pretendió conseguir una racionalización en el reparto de "canonie mansionarie et vestiaria et portiones mansionarie", buscando con ello una mejora de la gestión tanto material como espiritual de la Iglesia conquense. Se intentará evitar que la posesión de varios beneficios por un mismo eclesiástico sea práctica habitual, y se exigirán seis meses al menos de residencia en la Iglesia conquense para poder recibir la renta del vestiarium ${ }^{32}$.

Una legislación algo más amplia y detallada sobre la residencia es la que se recoge en unos estatutos promulgados por el obispo don Mateo Reinal y el cabildo catedralicio en 1250. En primer lugar se establece que todos los beneficiados habrán de residir durante un año íntegro y continuado para tener derecho a los frutos de su canonjía o porción. Si durante este primer año se ausentasen un solo día, al año siguiente tendrán que comenzar de nuevo desde el principio el periodo completo de residencia obligatoria anual en Cuenca para poder tener derecho a los frutos de su beneficio. En cuanto a la renta concreta del vestuario, se ratifica la norma de obligatoriedad de residencia durante seis meses para poder tener derecho a ella: "Quod canonici seu etiam persone qui per sex menses utiles in ecclesia residentiam non fecerint nichil vestiarii percipiant ${ }^{133}$. El 23 de julio de 1287 esta norma será confirmada de nuevo ${ }^{34}$.

Con todo, en ocasiones algunas de las normas hasta ahora referidas se quedarían en pura y simple teoría al entrar en juego el fenómeno de la acumulación de múltiples beneficios por una misma persona, situación en la cual muchas veces acababa produciéndose un inevitable absentismo que frecuentemente contaba con la correspondiente aprobación y dispensa

\footnotetext{
${ }^{32} \mathrm{ACC}$, caj. 4, n" 65.

${ }^{33} \mathrm{ACC}$, caj. $5, \mathrm{n}^{\circ} 86$.

${ }^{34} \mathrm{ACC}$, Necrologio-Obituario, f. $64 \mathrm{v}$.
} 
pontificia. Desde luego, la obligatoriedad de residencia en la catedral se vio pronto limitada por numerosas excepciones que contaban con un claro respaldo legal. Una de ellas era el caso de los beneficiados que acudiesen a estudiar fuera de la ciudad, situación que ya se contempla en los estatutos de San Julián de 1201. Ya para épocas posteriores contamos con numerosos ejemplos de dispensas pontificias otorgadas a favor de estudiantes que poseían prebendas en la catedral conquense ${ }^{35}$. Esta corriente migratoria del clero catedralicio hacia las universidades peninsulares y extranjeras, iniciada en el siglo XIII, se intensificaría a partir los decenios centrales de la siguiente centuria.

\section{EL CABILDO CATEDRALICIO \\ Y SU PARTICIPACIÓN \\ EN EL SERVICIO LITÚRGICO DE LA CATEDRAL}

Sin duda la misión básica, aunque no la única, del cabildo catedralicio era contribuir al engrandecimiento del servicio litúrgicơ de la catedral. A ello se añadían otras funciones como eran auxiliar al obispo en el gobierno diocesano, regular la organización interna del propio colectivo y encargarse de la gestión económica de los bienes de la mesa capitular, siendo también necesario tener muy en cuenta la funcionalidad sociopolítica que intrínsecamente poseía la institución capitular.

Los miembros del cabildo debían, en teoría, asistir al rezo de al menos alguna de las horas canónicas del oficio divino: maitines, laudes, prima, tercia, sexta, nona, vísperas y completas. Precisamente una parte importante del beneficio capitular se percibía por raciones, y su percepción estaba supeditada a la asistencia o no de los capitulares al rezo de cada hora, misas u otros actos de culto.

Por asistir al rezo de cada hora los componentes del cabildo catedralicio cobraban pequeñas cantidades de maravedís cuyo montante varió

\footnotetext{
${ }^{35}$ Así, por citar algún ejemplo, el 27 de julio de 1327 Juan XXII concede una dispensa pontificia a Juan de Luna, canónigo conquense, para que pueda percibir los frutos de todos sus beneficios por un trienio, tiempo durante el cual cursará disciplinas escolásticas en un Estudio General. G. Mollat, Jean XXII. Lettres Communes, París, 1904-1947, VI, n 29359. Y el 9 de septiembre de 1330 se otorga de nuevo a Juan de Luna, canónigo conquense, facultad para recibir los frutos de sus beneficios por otro trienio, estando ausente en el Estudio General de París u otro Estudio General. Ibid., IX, nº 50831 .
} 
de unas épocas a otras, siendo mayor o menor según la categoría jerárquica del cargo ocupado en el cabildo. Además no todas las horas estaban dotadas con la misma cantidad de maravedís, pues había algunas en las que la renta a cobrar era mayor que en otras. Así, por ejemplo, la maitinada era la hora por la que más se cobraba, lo cual sin duda estaba motivado por el deseo de paliar el frecuente absentismo que se producía en el rezo de esta hora.

En lo que atañe a la colocación de las dignidades en el coro, siempre se mantuvo invariable, siendo la siguiente:

Coro del obispo

1. Arcediano de Cuenca

2. Chantre

3. Arcediano de Alarcón

4. Tesorero

5. Abad de la Sey (siglo XV)

6. Arcipreste (desde 1507)
Coro del deán

1. Deán

2. Arcediano de Huete

3. Arcediano de Moya

4. Maestrescuela

5. Abad de Santiago (siglo XV)

Esta ordenación ya figura en un documento del obispo don Gonzalo García Gudiel emitido el 14 de julio de $1285^{36}$, exceptuados, por supuesto, los dos abades y el arcipreste, que aún no existían. También sabemos que en la parte alta del coro se sentaban los canónigos y beneficiados, y en la parte baja los capellanes y mozos de coro $^{37}$.

En cuanto a las fiestas y procesiones que se celebraban en la catedral, para las primeras hay que señalar que se dividían en dobles, solemnes de seis capas, de cuatro capas, de dos capas y simples, mientras que las procesiones podían ser solemnes, con órgano y simples ${ }^{38}$.

\footnotetext{
${ }^{36} \mathrm{ACC}$, caj. 11, no 205.

${ }^{37}$ ACC, Actas Capitulares de 1448, ff. 22r-24r.

${ }^{38}$ Una relación bastante completa de las fiestas y procesiones que se celebraban en la catedral puede verse en el trabajo de J. TRENCHS OdENA, El Necrologio-Obituario de la catedral de Cuenca, "Anuario de Estudios Medievales", 12 (1982), pp. 376-379.
} 


\section{RASGOS GENERALES \\ DEL PATRIMONIO RURAL Y URBANO DEL CABILDO CATEDRALIC'O DURANTE LOS SIGLOS XII Y XIII}

\section{Las propiedades rurales}

Ya en pleno siglo XII comenzaría el proceso de formación e incremento constante del patrimonio rural del cabildo. Así, desde la fundación del obispado hasta fines del siglo XIII el cabildo catedralicio lograría hacerse con más de 15 heredades, que se encontraban en Uclés, Huete, Noheda, Huércemes, Olmeda, Villaverde, Villalba, Mariana, Altarejos, Olmedilla, Villar de Cantos, Cuenca y otros lugares que la documentación no especifica, tratándose de propiedades que fueron donadas sobre todo por obispos, canónigos y particulares.

Durante este periodo el cabildo también obtendría al menos 17 viñas, situadas sobre todo en las proximidades de Cuenca. Estas viñas serían donadas fundamentalmente por miembros del propio colectivo capitular y por particulares, a cambio de aniversarios.

Asimismo, en esta etapa el cabildo obtuvo 11 huertos, casi todos muy próximos a Cuenca, y sobre todo en la hoz del Huécar. Bastantes de estos huertos fueron donados por obispos, y otros por canónigos y particulares. También hay que hacer mención de otros bienes que recibiría el cabildo: dos hocinos en la hoz del Huécar, cedidos por canónigos; varias zumaqueras que se obtuvieron en Cabeza Molina por donación de un particular; ciertas posesiones que deja un obispo en Cañete y, finalmente, los bienes que dejan cinco canónigos en Mohorte, Mariana y Cuenca ${ }^{39}$.

En cuanto a las donaciones de bienes raíces hechas por obispos, su finalidad, en unos casos, fue el sustento material de los miembros del cabildo mediante la anexión de rentas al refectorio y vestuario, mientras que otras veces tuvieron una significación espiritual al incentivar la asistencia a la hora más difícil del culto divino: la maitinada. Finalmente, otras donaciones se dirigieron a honrar la memoria de algún santo, tal como sucedió con la

\footnotetext{
${ }^{39}$ A. Chacón GómeZ-Monedero, El patrimonio rural de la Iglesia de Cuenca. Siglos XIIXIII, revista "Cuenca", 30 (1987), pp. 67-68. En este trabajo se recoge una relación completa de los diversos tipos de propiedades rurales que fueron donadas al cabildo catedralicio durante los siglos XII y XIII.
} 
dotación de la fiesta de Santa Catalina que hizo el obispo don Pedro Lorenzo en $1265^{40}$.

Durante este periodo solamente se conservan testimonios de cinco canónigos que hicieron donaciones de bienes rurales al cabildo, y en todos los casos fue a cambio de capellanías o aniversarios.

También para esta etapa sólo encontramos dos donaciones hechas al cabildo catedralicio por concejos. La primera es la realizada por el concejo de Alarcón el 11 de marzo de 1229 de una heredad en Villar de Cantos. La segunda es la donación del lugar de Valtablado con todos sus términos que el 23 de febrero de 1231 hizo el concejo de Cuenca al cabildo ${ }^{41}$. Respecto a las donaciones de bienes rurales a favor del cabildo catedralicio hechas por particulares, se conservan un total de cinco casos, siempre a cambio de aniversarios ${ }^{42}$.

Mención especial merece la posesión, desde el siglo XIII, de algunos molinos hidráulicos por parte de la institución capitular. Dentro de las donaciones recibidas por el obispo y cabildo catedralicio, ya en tiempos de Alfonso VIII, los molinos hidráulicos jugaron un importante papel de cara a la molturación del grano. En efecto, a la vez que tiene lugar el proceso repoblador, y formando parte del mismo, se desarrolla una intensa actividad constructora de molinos hidráulicos, tanto en su modalidad de molinos harineros como traperos. En Cuenca se percibe sobre todo una fuerte concentración de instalaciones en el corto tramo del Júcar que bordea la ciudad $^{43}$.

Durante los siglos XII y XIII el destinatario más frecuente de las transmisiones de molinos hidráulicos resultó ser, con mucho, la Orden de Santiago (13 sobre un total de 40 transacciones documentadas), seguida por la sede episcopal conquense ( 8 transacciones) y el cabildo catedralicio (también 8 transacciones). Al lado de estas instituciones, los eclesiásticos y laicos particulares, monasterios, Orden de Calatrava y concejos no jugaron sino un triste papel (11 transacciones repartidas entre todos ellos). Ahora bien, el ritmo de adquisición de los ingenios hidráulicos fue distinto según

\footnotetext{
${ }^{40}$ Ibid., pp. 59-60.

${ }^{4} I$ Ibid., pp. 62-63.

t2Ibid., p. 63.

${ }^{43}$. AGUadÉ NiETO, Molino hidráulico y sociedad en Cuenca durante la Edad Media (11771300). "Anuario de Estudios Medievales", 12 (1982), pp. 257-263.
} 
los casos. Mientras que en la Orden de Santiago el proceso ya se inicia en la segunda mitad del siglo XII, y se interrumpe bruscamente en torno a 1225, para no resurgir ya, al parecer, durante el resto del siglo XIII, ocurriendo algo similar con la sede episcopal, si bien con un cierto retraso, en cambio el cabildo, cuyo papel en este sector de la economía comenzó más tarde, fue la entidad que actuó con mayor regularidad en las adquisiciones: una en el periodo 1201-1225, tres en el periodo 1226-1250, otras tres entre 1251-1275, y de nuevo una entre los años 1276-1300

Este régimen de monopolio en que funcionaba el sistema de explotación de molinos a veces dará lugar a ciertos conflictos por su control entre las instituciones que ejercían la propiedad. Un ejemplo de ello vendía dado por la fuerte oposición de intereses que en este sentido se produjo entre el cabildo y la Orden de Santiago en época del obispo Gonzalo Juanes ${ }^{45}$.

Por otro lado es necesario poner de manifiesto que, a medida que avance el siglo XIII, tanto los santiaguistas como el cabildo transformarán en batanes algunos de sus molinos harineros, de forma paralela al desarrollo inicial de la industria textil conquense ya durante esta centuria, preludio de la importante expansión textil que se producirá en el siglo $X^{46}$. Así, por ejemplo, en 1275 Domingo Pérez, arcediano de Cuenca, llegaría a un acuerdo con el cabildo catedralicio para transformar unos molinos harineros de Villalba en molinos traperos, y en 1290 el cabildo estaba construyendo en Valdeganga y Olivares unos molinos que, al menos en parte, debían de ser traperos ${ }^{47}$.

En lo que respecta a la posible utilización dada por el cabildo a sus molinos harineros, aunque carecemos de datos concretos al respecto, parece probable su empleo para la transformación en harina de parte de las grandes cantidades de cereal que el cabildo percibía anualmente en concepto de rentas eclesiásticas.

Desde luego, durante los siglos XII y XIII, los bienes rurales serán predominantes, si bien, tal como más adelante se verá, ya desde fines del

\footnotetext{
${ }^{44}$ Ibid., p. 269.

${ }^{45}$ P. Iradiel Murugarren, Bases económicas del hospital de Samtiago de Cuenca, "Anuario de Estudios Medievales", 11 (1981), pp. 191-192.

${ }^{\text {th }}$ Ya para fines del siglo XIII sabemos de la existencia de bodegas, tinas y cubas junto al Huécar, en una zona próxima a la Puerta de Valencia, que servían sin duda para la tintura de paños.

${ }^{47}$ S. Aguadé Nieto, op. cit., p. 271
} 
XII se iniciaría también la formación de un patrimonio urbano que no tardaría en adquirir gran relieve. A la vista de todo lo dicho hasta ahora surge de inmediato una pregunta: ¿Cómo explotó durante este periodo el cabildo todo este patrimonio rural en constante incremento?. Sólo contamos para esta etapa con seis documentos que hablan de explotación indirecta. Estos contratos se llevan a cabo entre el cabildo y algunos eclesiásticos o laicos. En unos casos se trata de arrendamientos vitalicios y en otros de contratos enfitéuticos.

Si exceptuamos un arrendamiento vitalicio de una viña entre el cabildo y Pedro Gil, a través de cual éste pagaría 13 mencales anuales el día de Todos los Santos, y que está datado en 1226, los otros cinco contratos son más tardíos, situándose concretamente entre 1270 y 1282. En este último año el cabildo arrendaría de por vida al obispo don Gonzalo, junto con unas tiendas en Cuenca, un huerto en la hoz del Huécar por 28 mrs. anuales, y en 1280 se había realizado otro arrendamiento vitalicio, de la heredad de Noheda, a Ferrant López, arcediano de Alarcón, a cambio del pago anual de $320 \mathrm{mrs}$. y otras muchas condiciones que se especifican en el contrato. En cuanto a los arrendamientos enfitéuticos, los tres ejemplos que se han conservado datan de 1270, y en todos los casos se arrienda una viña: el 4 de febrero a Miguel Pérez, carpintero, "en el pago de la Fuent Sancta"; el 27 de abril a Yagüe, el pisador, "entre la carretera que va a Nohales y la que va a Arcos"; y el 10 de agosto a Domingo Martínez, vecino de Valdemorillo, "en el pago tras la Fuent Sancta". Esta escasez de contratos que hablen de explotación indirecta, según algún autor, sería un claro indicio de que la inmensa mayoría del patrimonio capitular durante este periodo era explotado directamente por el cabildo ${ }^{48}$.

No obstante, esta opinión debe ser matizada a la luz de toda una serie de importantes disposiciones que sobre arrendamientos aparecen recogidas en los ya mencionados estatutos que otorgó San Julián al cabildo en 1201. En ellos se establece, entre otras cosas, que, según deseo expreso

\footnotetext{
${ }^{48} \mathrm{~A}$. CHACÓN, El patrimonio rural, pp. 69-71. En cuanto a los tres contratos enfitéuticos que se han indicado, las condiciones que se fijan en ellos son muy parecidas en todos los casos. La cesión se hace a perpetuidad, pudiéndose transmitir libremente a los herederos u otras personas, siempre y cuando éstos respeten las condiciones aceptadas por el primer arrendatario. La renta que se exige es mixta: por un lado se ha de entregar una cantidad anual en dinero, que se fija en un mencal por aranzada, y por otra parte se pagará una renta en especie, que será el diezmo del fruto que produzca la viña. Este pago se habrá de hacer efectivo ocho días antes de Navidad. Ibid., p. 71.
} 
del cabildo, se puedan arrendar las heredades y viñas vinculadas a los aniversarios, tanto las que al presente se tienen como las que se posean en un futuro, con la condición de que el canónigo que actúe como arrendatario pague al cabildo el dinero correspondiente al aniversario en la víspera de su celebración, y que en caso contrario sea obligado a efectuar la paga doblada. Además todo canónigo estará obligado a tratar correctamente la heredad de que se haga cargo, que tendrá derecho a poseer en usufructo durante toda su vida hasta que muera, momento en que volvería a posesión del cabildo.

Estas disposiciones del año 1201 revisten gran relieve, y es probable que tras el establecimiento de dichas normas la actuación de los propios canónigos como arrendatarios de bienes del cabildo fuese frecuente, aunque no se nos hayan conservado muchos testimonios documentales sobre ello. Lo cierto es que, ya en una fecha muy temprana, San Julián y el cabildo catedralicio se dieron cuenta de que para la institución capitular un sistema muy cómodo que podía utilizarse de cara a explotar sus bienes consistía en el arrendamiento de éstos a los propios canónigos. En este caso, pues, ya nos encontraríamos ante un sistema indirecto de explotación y, evidentemente, si el cabildo estableció normas al respecto no pudo ser por otro motivo que porque ya entonces estaba comenzando a desarrollarse una clara tendencia a la explotación indirecta mediante arrendamientos, aunque hay que observar que esta forma indirecta de explotación no se afianzaría definitivamente hasta el siglo XIV. Por otro lado, durante el siglo XIII el sistema de arrendamientos ya se daba también en otros cabildos catedralicios castellanos.

Con todo, también es cierto que durante este periodo inicial el trabajo de los dependientes del cabildo catedralicio debió de tener un cierto grado de importancia de cara a la explotación directa de algunos bienes capitulares de origen rural. La existencia de un contingente de cierto relieve formado por hombres que tenían la condición de paniaguados o dependientes del cabildo la conocemos gracias a un documento del 7 de marzo de 1207 a través del cual, y a instancias del obispo San Julián, se realizó una concordia entre el cabildo catedralicio y el concejo conquense de cara a regular en qué casos los hombres dependientes del cabildo debían someterse a la justicia eclesiástica y en cuáles otros estarían sujetos a la jurisdicción laica. El simple hecho de que se realice un acuerdo de estas características nos está indicando que el número de dependientes del cabildo no debía de ser despreciable. En el documento se utiliza la expresión "homo canonici" para 
aludir a este elemento dependiente, que estaba integrado por yugueros, hortelanos, molineros, pastores y otros hombres al servicio del cabildo ${ }^{49}$.

Muchos de estos hombres vivían en las propias casas de los canónigos, bajo su directa dependencia. En cuanto al papel concreto que jugaron en la explotación directa de los bienes capitulares, las referencias que tenemos se reducen prácticamente al documento antes señalado. Así, los yugueros y hortelanos se encargarían de labrar la tierra, los molineros de trabajar los molinos y los pastores de cuidar los rebaños. Además, si se daba el caso de que un canónigo tomase en arrendamiento una propiedad del cabildo, su explotación, lógicamente, también correría a cargo del "homo canonici". Pero, si bien en el siglo XIII este elemento dependiente tuvo cierto relieve, en la centuria siguiente pasaría a un plano secundario al imponerse el arrendamiento como forma de explotación del patrimonio capitular.

Por último no queda sino destacar que, además de las importantes rentas que el cabildo catedralicio obtuvo de la explotación de este patrimonio rural, la institución capitular también se vio beneficiada por la temprana posesión de toda una serie de privilegios económicos, sobre todo de origen real, así como exenciones diversas, lo cual constituyó un complemento esencial a las antedichas rentas capitulares. Las salinas, y en menor medida los portazgos, aportaron ciertos ingresos al cabildo, que también percibió, aparte del diezmo, otros pequeños derechos eclesiásticos, gozando asimismo de la exención del pago de numerosos pechos reales.

\section{Las propiedades urbanas}

Ya desde fines del siglo XII comenzará el proceso de formación e incremento constante del patrimonio urbano del cabildo, fundamentalmente gracias a donaciones recibidas tanto de eclesiásticos, sobre todo capitulares $\mathrm{y}$ algunos obispos, como de laicos vecinos de Cuenca, a cambio de aniversarios y capellanías. Algunos testimonios de que disponemos sobre estas donaciones durante los siglos XII y XIII son los siguientes:

-Entre otras donaciones hechas al cabildo catedralicio el 30 de enero de 1196 por Bonus Homo, sacristán de la catedral, figuran varias casas, una

\footnotetext{
${ }^{49} \mathrm{ACC}$, caj. 2, no 33.
} 
cuba y palomares en Cuenca, a cambio de la celebración de aniversa$\operatorname{rios}^{50}$.

-También en 1196 el canónigo don Gil donó al cabildo una casa cerca de la catedral, seis tiendas y nueve tablas de carnicería, con la carga de tres aniversarios ${ }^{51}$.

-Antes de 1224 el canónigo don Asensio había dejado al cabildo unas casas en Cuenca a cambio de un aniversario ${ }^{52}$.

-El 26 de mayo de 1226 don Mateo Donoro y su mujer donaron al cabildo, entre otras cosas, unas casas en el barrio de San Pedro de Cuenca, a cambio de aniversarios ${ }^{53}$. del cabildo ${ }^{54}$

-En 1230 nos encontramos con la mención de unos baños propiedad

-El 12 de diciembre de 1256 don Diego y su mujer donaron al cabildo unas casas en Cuenca, a cambio de tres aniversarios, disfrutándolas en usufructo mientras vivan ${ }^{55}$.

-El 13 de mayo de 1258 don Mateo, obispo de Burgos, confirmó al cabildo de Cuenca las donaciones que les había hecho siendo obispo de esta ciudad, y entre los bienes donados figuran varias casas delante de la catedral $^{56}$.

-El 27 de octubre de 1263 Juan de la Tienda donó al cabildo varias tenerías y casas en el Barrio Nuevo, a cambio de una capellanía, aniversario y procesión ${ }^{57}$.

-El 21 de diciembre de 1264 el obispo don Pedro Lorenzo haría donación al cabildo, para la maitinada, y entre otras cosas, de varios grupos de casas en las cercanías de la catedral ${ }^{58}$.

\footnotetext{
${ }^{50}$ C. SANZ y Díaz, Reseña cronológica de algunos documentos contenidos en el Archivo Catedralicio de Cuenca, Cuenca, 1974, $n^{\circ} 25$

${ }^{51}$ Ibid., n' 27.

${ }^{52} \mathrm{ACC}$, caj. $4, \mathrm{n}^{\circ} 55$.

${ }^{53} \mathrm{C}$. SANZ y Díaz, op. cit., $\mathrm{n}^{\circ} 65$.

${ }^{54} \mathrm{ACC}$, caj. 4, no 68.

${ }^{55} \mathrm{C}$. SANZ Y DíaZ, op. cit., $\mathrm{n}^{\circ} 92$.

${ }^{56} \mathrm{ACC}$, caj. 6, $\mathrm{n}^{0} 106$.

${ }^{57} \mathrm{C}$. SANZ y DÍAZ, op. cit., $\mathrm{n}^{0} 106$.

${ }^{58}$ ACC, caj. 7, no 127
} 
-El 26 de enero de 1284 el cabildo recibió unas tiendas en la Correría a través de una manda testamentaria hecha por doña Mayor, mujer de Martín García, a cambio de la celebración de cuatro aniversarios ${ }^{59}$.

-El 6 de febrero de dicho año de 1284 el maestro Domingo Juan hizo entrega al cabildo de unas casas en Cuenca que les había dejado su tío don Millán, con la carga de un aniversario ${ }^{60}$.

-El 19 de julio de 1286 Rodrigo García, arcediano de Huete, donó al cabildo, entre otras cosas, unas casas y dos tiendas en Cuenca, a cambio de aniversarios ${ }^{61}$.

-El 7 de diciembre de 1292 Mateo Pérez, vecino de Cuenca, donó al cabildo unas casas en la collación de San Pedro, a cambio de aniversarios $^{62}$

-El 4 de enero de 1297 el maestro Juan de Montalbán, arcediano de Huete, haría donación al cabildo de unas casas en Cuenca con la carga de una misa de Santa María a celebrar cada año por don Gonzalo, arzobispo de Toledo, y un aniversario a celebrar tras su muerte ${ }^{63}$.

No se trata, ni mucho menos, de todas las donaciones de bienes urbanos hechas a favor del cabildo hasta fines del siglo XIII, dado que es seguro que para algunas de ellas no se nos han conservado las referencias documentales. Como puede apreciarse, en todos los casos arriba expuestos las donaciones fueron realizadas con fines religiosos, fundamentalmente a cambio de la celebración de aniversarios. Asimismo, se observa que además de las casas también figuran algunas propiedades comerciales, como tablas de carnicería y tiendas.

En cuanto al modo de explotación de este patrimonio urbano, ya desde fechas muy tempranas comenzaría a implantarse la fórmula del arrendamiento. Así, por ejemplo, en 1224 el cabildo catedralicio arrendaría de por vida a doña $\mathrm{W}$. las casas que les había dejado el canónigo don Asensio para su aniversario, al precio de diez mencales anuales ${ }^{64}$. Ya en la segunda mitad del siglo, entre los bienes arrendados el 6 de agosto de 1282

\footnotetext{
${ }^{59}$ C. SANZ y DíaZ, op. cit., no 179.

${ }^{60}$ Ibid., n' 180.

${ }^{6}$ Ibid., n' 184.

${ }^{62}$ Ibid., $\mathrm{n}^{0} 201$.

${ }^{6.3}$ IBID., $\mathrm{n}^{\mathrm{0}} 209$

${ }^{64} \mathrm{ACC}$, caj. $4, \mathrm{n}^{0} 55$.
} 
por el cabildo catedralicio al obispo de Cuenca don Gonzalo García figuran unas tiendas en la ciudad. En esta ocasión el arrendamiento también tuvo carácter vitalicio ${ }^{65}$. Así, pues, vemos que los arrendatarios de propiedades urbanas del cabildo podían ser tanto laicos como eclesiásticos.

Especial atención merece el importante control que el cabildo catedralicio, ya desde muy poco tiempo después de su fundación, comenzaría a ejercer sobre el comercio de la carne en la ciudad mediante la incorporación a su patrimonio de un buen número de tablas de carnicería. En efecto, entre enero y diciembre de 1194 el canónigo conquense don Gil compró un total de once tablas de carnicería al precio global de $454 \mathrm{mrs} .{ }^{66}$, y en 1196 este mismo canónigo donaría al cabildo, entre otros bienes urbanos, nueve de las once tablas de carnicería que había adquirido dos años atrás, reservándose el usufructo vitalicio de ocho de ellas ${ }^{67}$.

El cabildo pronto mostraría interés por la consecución de unas rentas derivadas de la explotación de estas tablas de carnicería. Así, cuando el canónigo don Gil lleva a cabo su donación de 1196, mientras se reserva el usufructo vitalicio de una casa, cinco tiendas y ocho tablas de carnicería, hace cesión inmediata al cabildo de la plena propiedad de otra tienda y otra tabla "ut ipsi recipiant omnes redditus quos inde potuerint habere". Y en el libro de cuentas capitulares de 1337 figura que este año el cabildo obtenía 30 mrs. por el arrendamiento de cada una de las ocho tablas de carnicería que se mencionan ${ }^{68}$. Así, pues, parece clara la explotación de este tipo de propiedades comerciales mediante el sistema de arrendamiento, al igual que sucedía con el resto de bienes urbanos del cabildo.

Ante todo hay que destacar que, ya desde fines del siglo XII, el cabildo catedralicio lograría hacerse con el control de la mayor parte de las tablas de carnicería de la ciudad. Esta situación aparece plenamente consolidada en la primera mitad del siglo XIV, momento en que la Orden de Santiago también figura como propietaria de algunas tablas de carnicería en Cuenca, aunque de mucho menor relieve que las que poseía el cabildo. Así, pues, en estas fechas existía un claro proceso de señorialización del

\footnotetext{
${ }^{65} \mathrm{ACC}$, caj. 11, n⿳0 196.

${ }^{66}$ S. AguAdÉ Nieto y Ma D. CABAÑas GonzÁlez, Comercio y sociedad urbana en la Castilla medieval. La comercialización de la carne en Cuenca (1177-1500), "Anuario de Estudios Medievales", 14 (1984), p. 490.

${ }^{67}$ Ibid., p. 496.

${ }^{68}$ Ibid., p. 498.
} 
comercio de la carne, y como consecuencia de ello los comerciantes carniceros aparecen convertidos, al menos parcialmente, en arrendatarios, con lo que una parte sustancial de los beneficios obtenidos de la comercialización de la carne se canaliza hacia la entidad señorial propietaria ${ }^{69}$.

\section{CONCLUSIÓN}

Contando con la previa autorización pontificia, otorgada por Lucio III el 15 de mayo de 1183, muy poco después, el 28 de julio del mismo año, el obispo electo don Juan Yáñez instituyó el cabildo catedralicio conquense que, formado inicialmente por canónigos regulares, como muy tarde a mediados del siglo XIII ya estaría plenamente secularizado. Fuertemente jerarquizado en su seno desde los primeros momentos, a su cabeza estaban las llamadas dignidades o personas, que inicialmente fueron ocho. Seguía en importancia el cabildo de canónigos, la corporación catedralicia por excelencia, del que casi siempre formaron parte las dignidades en función de la posesión de alguna canonjía. Finalmente estaban los racioneros y mediorracioneros o compañeros.

En cuanto al beneficio capitular, estuvo integrado por ingresos procedentes de diversas fuentes de renta, siendo su cuantía económica mayor o menor en función del grado jerárquico ocupado en el cabildo. En general, los componentes del beneficio fueron uno o varios préstamos situados sobre las rentas decimales en algunas parroquias de la ciudad o diócesis, el vestuario y una o varias raciones situadas sobre las rentas de la mesa capitular.

La percepción del beneficio estaba teóricamente sujeta a toda una serie de normas sobre residencia y cumplimiento de deberes litúrgicos en la catedral que pronto comenzaron a ser precisadas con exactitud. No obstante, con frecuencia algunas de estas normas se quedarían en pura y simple teoría al entrar en juego numerosas situaciones de absentismo que no tardaron en contar con el respaldo pontificio.

Finalmente, en lo que respecta al patrimonio del cabildo, ya desde los primeros momentos estuvo compuesto por un conjunto de bienes y rentas muy diversos, tanto rurales como urbanos, si bien los ingresos rurales serán

\footnotetext{
${ }^{69}$ Ibid., p. 499.
} 
los más importantes. El impulso inicial a este patrimonio vino dado por el proceso de dotación regia, sobre todo durante el reinado de Alfonso VIII, pero pronto comenzaron también las frecuentes donaciones al cabildo por parte de sus propios miembros, los obispos conquenses, otros eclesiásticos y numerosos laicos, tanto nobles como simples vecinos de Cuenca, todo lo cual determinó el constante incremento de este patrimonio, para cuya explotación, ya durante el siglo XIII, cada vez se irá afianzando más el sistema de arrendamiento.

\section{RÉSUMÉ}

Dans ce bref travail on analyse, très succintement l'organisation administrative et économique du chapitre de la cathédrale de Cuenca dès sa fondation à la fin du XII ${ }^{e}$ siècle et tout au long du XIII ${ }^{e}$ siècle. D'abord on étudie l'origine de cette institution encadrée dans le processus de création du diocèse de Cuenca, ensuite on analyse la difference hiérarchique entre ses membres et le rôle de ceux-ci dans le culte de la cathédrale et du gouvernement diocésain, et finalement on fera l'étude des principales bases économiques et du processus initial de formation du patrimoine rural et urbain du chapitre ainsi que sa forme d'exploitation.

\section{SUMMARY}

In this blicf essay it is analysed, quite concisely, the economic and administrative organization of the chapter of the cathedral in Cuenca from its foundation at the end of the XIIth century and throughout the whole XIIIth century. On the one hand, it is studied the origin of this institution within the foundational process of the diocese of Cuenca, and on the other, we will analyse the hierarchical differentiation among its members and the role played by them in the worship of the cathedral and diocesan government, ending by studying the main economic basis and the initial process of formation of the rural and urban patrimony of the chapter, and also its way of exploitation. 